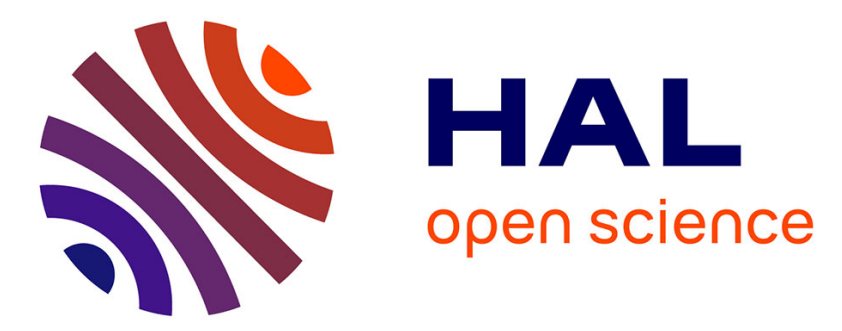

\title{
Real-Time Energy Management of Battery/Supercapacitor Electric Vehicles Based on an Adaptation of Pontryagin's Minimum Principle
}

Bao Huy Nguyen, Ronan German, Joao Pedro Fernandes Trovao, Alain Bouscayrol

\section{To cite this version:}

Bao Huy Nguyen, Ronan German, Joao Pedro Fernandes Trovao, Alain Bouscayrol. Real-Time Energy Management of Battery/Supercapacitor Electric Vehicles Based on an Adaptation of Pontryagin's Minimum Principle. IEEE Transactions on Vehicular Technology, In press, pp.1-1. hal-01953209

\author{
HAL Id: hal-01953209 \\ https://hal.science/hal-01953209
}

Submitted on 12 Dec 2018

HAL is a multi-disciplinary open access archive for the deposit and dissemination of scientific research documents, whether they are published or not. The documents may come from teaching and research institutions in France or abroad, or from public or private research centers.
L'archive ouverte pluridisciplinaire HAL, est destinée au dépôt et à la diffusion de documents scientifiques de niveau recherche, publiés ou non, émanant des établissements d'enseignement et de recherche français ou étrangers, des laboratoires publics ou privés. 


\title{
Real-Time Energy Management of Battery/Supercapacitor Electric Vehicles Based on an Adaptation of Pontryagin's Minimum Principle
}

\author{
Bảo-Huy Nguyễn, Ronan German, João Pedro F. Trovão, Senior Member, IEEE, and Alain
} Bouscayrol, Member, IEEE

\begin{abstract}
The combination of batteries and supercapacitors is promising in electric vehicles context to minimize battery aging. Such a system needs an energy management strategy (EMS) that distributes energy in real-time for real driving cycles. Pontryagin's minimum principle (PMP) is widely used in adaptive forms to develop real-time optimization-based EMSs thanks to its analytical approach. This methodology leads to an off-line optimal solution which requires an extra adaptive mechanism for real-time applications. In this paper, a simplification of the PMP method is proposed to avoid the adaptation mechanism in real-time. This new EMS is compared to well-known conventional strategies by simulation. Furthermore, experimental results are provided to assess the real-time operation of the proposed EMS. Simulation and experimental results prove the advantages of the proposed approach by a reduction up to $50 \%$ of the batteries rms current on a real-world driving cycle compared to a battery-only EV.
\end{abstract}

Index Terms-Energetic macroscopic representation, Energy storage system, Hardware-in-the-loop, Optimal control.

\section{NOMENCLATURE}

Variables

$\begin{array}{llll}C & \text { Capacitance } & r & \text { Resistance } \\ F & \text { Force } & s & \text { Laplace operator }\end{array}$

This work was supported by the Canada Research Chairs Program, the National Sciences and Engineering Research Council of Canada, and also with the support of the "Service de Coopération et d'Action Culturelle du Consulat Général de France à Québec" within the Samuel-De Champlain Program. This work has been achieved within the framework of CE2I project co-financed by European Union with the financial support of European Regional Development Fund (ERDF) and the French Region of Hauts-de-France. The review of this paper was coordinated by Dr. Mohamed Benbouzid.

B.-H. Nguyễn is with Department of Electrical Engineering and Computer Engineering, Université de Sherbrooke, Sherbrooke, QC, J1K 2R1, Canada, and also with the Laboratory of Electrical Engineering and Power Electronics, University of Lille, Villeneuve d'Ascq, 59655, France (e-mail: Bao.Huy.Nguyen@USherbrooke.ca).

R. German is with the Laboratory of Electrical Engineering and Power Electronics, University of Lille, Villeneuve d'Ascq, 59655, France (e-mail: Ronan.German@univlille.fr).

J. P. F. Trovão is with the Department of Electrical Engineering and Computer Engineering, Université de Sherbrooke, Sherbrooke, QC, J1K 2R1, Canada, and also with the Institute for Systems and Computers Engineering at Coimbra, Portugal (e-mail: Joao.Trovao@USherbrooke.ca).

A. Bouscayrol is with the Laboratory of Electrical Engineering and Power Electronics, University of Lille, Villeneuve d'Ascq, 59655, France (e-mail: Alain.Bouscayrol@univ-lille.fr).

$\begin{array}{llll}f, g, h & \text { General functions } & T & \text { Torque } \\ H & \text { Hamiltonian } & u & \text { Voltage } \\ i & \text { Current } & v & \text { Longitudinal velocity } \\ J & \text { Cost function } & w & \text { Control variable } \\ k & \text { Coefficient } & x & \text { State variable } \\ L & \text { Inductance } & \eta & \text { Efficiency } \\ m & \text { Modulation ratio } & \lambda & \text { Co-state variable } \\ M & \text { Mass } & \tau & \text { Time constant } \\ P & \text { Power } & \Omega & \text { Rotational speed }\end{array}$

\section{Subscripts}

\begin{tabular}{|c|c|c|c|}
\hline -bat & Battery & _nom & Nominal \\
\hline _cal & Calculated & _P & Proportional (control) \\
\hline _ch & Chopper & ref & Reference \\
\hline conv & Converter & res & Resistant \\
\hline _emu & Emulation & _rms & Root mean square \\
\hline$-f$ & Final & _roll & Rolling \\
\hline - & Integral (control) & _SC & Supercapacitor \\
\hline _init & Initial & $-^{\operatorname{trac}}$ & Traction \\
\hline LP & Low-pass filter & ${ }_{-\operatorname{trans}}$ & Transmission \\
\hline$-\mathrm{m}$ & Machine & _veh & Vehicle \\
\hline & Measurement & _wind & Wind \\
\hline
\end{tabular}

\section{INTRODUCTION}

耳 LECTRIC VEHICLES (EVs) are the future of our world due to limited fossil fuel sources and environmental issues.

Energy storage, however, has a direct impact on the autonomy and the price of an EV. Batteries cost, energy density, and especially life-time are crucial for EV market. Adding supercapacitors (SCs), which forms hybrid energy storage systems (H-ESSs), is a promising solution [1]. Being known as a kind of high power-density sources, SCs can support batteries to reduce the degradation caused by current peaks.

The H-ESSs requires an energy management strategy (EMS) to distribute the energy in a fair way between batteries and SCs. EMS is an interesting topic attracting numerous efforts reported in the literature. They can be classified into rule-based and optimization-based strategies [2], [3].

Rule-based EMSs can be fuzzy [4], [5] or deterministic [6][9], in which filtering strategy is among the most classical ones [10]-[13]. Rule-based EMSs are often simple and easy to be implemented in real-time. Nevertheless, these methods require knowledge about the system behaviors and/or developers' expertise. That leads to non-optimal solutions. 
On the other hand, optimization-based methods are more and more attractive due to their ability to minimize given cost functions. They are sorted as global optimal strategies and real-time sub-optimal ones [3]. Global optimal EMSs are often developed by dynamic programming (DP) [14], Pontryagin's minimum principle (PMP) [15]-[18], or other optimization methods e.g. [19]. These strategies are optimal, however, only for off-line simulation due to the need of knowing the driving cycle in advance. Methods like DP require high computational effort which is hard for real-time application.

By contrast, real-time EMSs are sub-optimal but usable for real-time operation. Many optimization methods have been applied for developing EMSs such as model predictive control (MPC) [20], meta-heuristic methods [21], or adaptive PMP [22]-[24]. They normally offer high performances for the managed systems. Their drawbacks are often on the complexity of the strategies. For instance, MPC and metaheuristic approaches need to do a lot of calculations to solve the optimization problems in every sampling time.

Adaptive PMP strategies, which are mostly $\lambda$-control [24], are less costly in terms of computational effort thanks to their analytical approach. The common way is to compute an openloop off-line optimal solution. A feedback of the state variable then leads to closed-loop adaptation of real-time evolutions. However, these methods require an important theoretical development based on a known-in-advance driving cycle that leads to sub-optimal solutions for real driving cycles not $a$ priori known. A new approach has been proposed without adaptation mechanism [25]. It consists in using a part of the PMP form including the state variable that indirectly induces a feedback (i.e. an adaptation). However, this method has been only studied in simulation; its real-time operation has not been demonstrated. Moreover, only a New European Driving Cycle (NEDC) driving cycle has been considered; its adaptation to other driving cycles has not been studied. Finally, no comparison with other real-time EMS was achieved.

The papers objective deals with an improvement and the positioning of the PMP-based EMS without adaptation mechanism proposed in [25]. First, the co-state variable is determined in a new way. Second, the proposed EMS is compared with other classical EMS with different driving cycles to define its performances. Finally, its real-time operation is demonstrated by experiments using a laboratory set-up.

Section II describes the studied H-ESS, including modeling, control organization, and conventional EMSs. Section III presents the new EMS. Comparisons with classical EMSs are provided by simulation in Section IV. Experimental validations of the proposed EMS are presented in Section V.

\section{CONVENTIONAL StRATEGIES OF THE STUDIED SySTEM}

\section{A. Studied System Description}

\section{1) Configuration}

The studied system is a semi-active battery/SCs H-ESS for EVs (Fig. 1). The batteries are coupled in parallel with a SCs subsystem. The SCs are connected in series with an inductor and a chopper. The H-ESS supplies the traction subsystem. Since this work focuses on the H-ESS, the traction subsystem is considered as an equivalent current source.

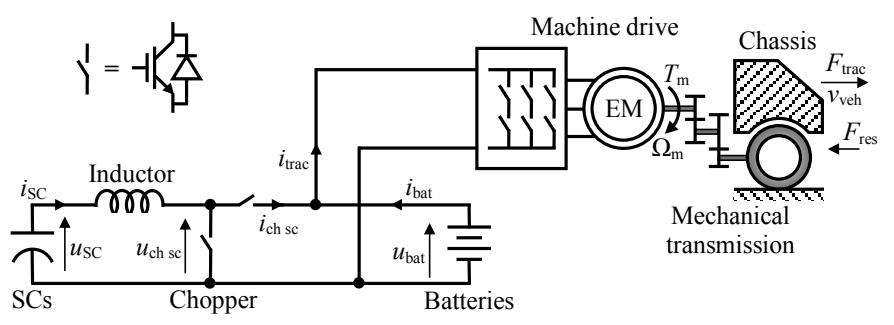

Fig. 1. Studied system: a semi-active battery/SC H-ESS for EVs.

\section{2) Modeling}

All the mathematical equations for modeling are provided in Table I. The model representation can be found in the previous work [25].

The batteries can be modeled by (1). It outputs the batteries voltage $u_{\text {bat }}$ and inputs the batteries current $i_{\text {bat. }}$. There is a voltage drop in the equivalent series resistance (ESR) $r_{\text {bat }}$. The ESR is in fact different in charging and discharging modes; and it is a non-linear function of the state-of-charge (SoC). The open-circuit voltage (OCV) $u_{\text {bat OC }}$ is also a non-linear function of the $\mathrm{SoC} S o C_{\text {bat }}$. In this work, the relationships $r_{\text {bat }}\left(S o C_{\text {bat }}\right)$ and $u_{\text {bat oc }}\left(S o C_{\text {bat }}\right)$ are given by look-up tables. The $\mathrm{SoC}$ is calculated by Coulomb counting with the capacitance $C_{\text {bat. }}$.

Unlike battery, the SoC of SC is proportional to its voltage. Thus, the SCs model can be simply given by (2) with their voltage $u_{\mathrm{SC}}$, current $i_{\mathrm{SC}}$. The current $i_{\mathrm{SC}}$ charges/discharges the $\mathrm{SCs}$ with the capacitance $C_{\mathrm{SC}}$. The $\mathrm{SC}$ resistance $r_{\mathrm{SC}}$ causes an internal voltage drop and is quite independent of the SCs SoC. In this study, the $r_{\mathrm{SC}}$ is given from the manufacture's datasheet.

The inductor, with its inductance $L$ and internal resistance $r_{\mathrm{L}}$, is modeled by (3); in which $u_{\mathrm{ch} \mathrm{sc}}$ is the chopper voltage.

The chopper model is expressed by (4). The voltages $u_{\text {bat }}$ and $u_{\mathrm{chsc}}$ are linked by the modulation function $m_{\mathrm{chsc}}$, as well as the current $i_{\mathrm{SC}}$ and $i_{\mathrm{ch} \mathrm{sc}}$.

Equation (5) models the parallel connection, in which $i_{\text {trac }}$ is the traction current. The machine drive subsystem imposes $i_{\text {trac }}$ given by (6) which is the static model of the electrical machine drive. The efficiency $\eta_{\mathrm{m}}$ of the electrical machine drive is given by an efficiency map [26].

The mechanical transmission, combining final drive ratio and wheel transmission, is modeled by (7). The vehicle chassis dynamics is addressed by the second Newton law of the relationship between the traction force, the resistant force, and the vehicle velocity given by (8). The total mass $M_{\text {veh }}$ is considered as the summation of the vehicle net weight and two passengers.

The environment imposes the total resistant force to the vehicle as a combination of rolling resistant force, air drag resistant force, and gravitational resistant force cause by slope as given in (9).

\section{3) Control Organization}

The control scheme can be systematically conducted by the inversion of the system [27]. It is realized by equations given in the bottom part of Table I. 
TABLE I

EQUATIONS FOR MODELING AND CONTROL OF THE STUDIED SYSTEM

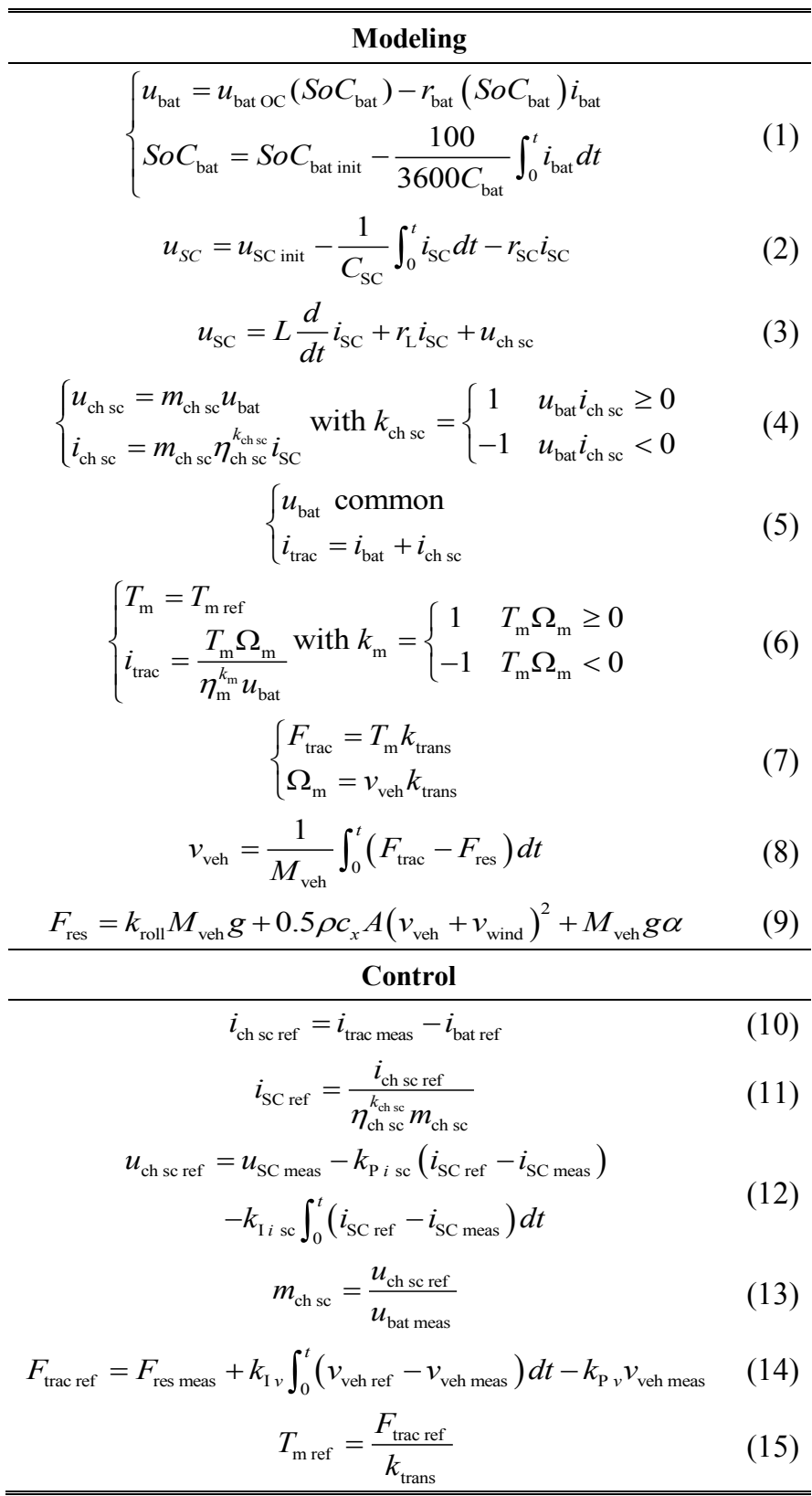

The coupling relationship can be directly inverted (10). The chopper current reference $i_{\text {chs ref }}$ is conducted from the batteries current reference $i_{\text {bat ref }}$ by compensating the measured traction current $i_{\text {trac meas }}$.

The $i_{\text {ch sc ref }}$ then enters to the direct inversion of the chopper current relationship which outputs the SCs current reference $i_{\mathrm{SC} \text { ref }}$ as in (11).

The indirect inversion of the inductor is achieved by a conventional proportional-integral (PI) current controller (12); in which $u_{\text {ch sc ref }}$ is the chopper voltage reference, $u_{\mathrm{SC} \text { meas }}$ the SCs voltage measurement, $i_{\mathrm{SC} \text { meas }}$ the $\mathrm{SCs}$ current measurement, $k_{\mathrm{P} i \text { sc }}$ and $k_{\mathrm{I} i \mathrm{sc}}$ the PI coefficients, respectively.

Finally, the modulation function $m_{\mathrm{ch}}$ sc is computed by (13) with the measured batteries voltage $u_{\text {bat meas }}$.

For control of vehicle dynamics, (8) is firstly inverted to obtain the velocity control loop. Since the chassis is an accumulation element which cannot be directly inverted, indirect inversion is required. It is realized by a closed-loop control (14) with the measurement of the vehicle velocity as the feedback. The electrical machine torque reference is then obtained by directly inverting the relationship (7) to obtain the reference torque (15).

\section{B. System Reduction for Energy Management}

Energy management is at the higher layer than local control. Besides, different layers have different dynamics that need to be treated by different sampling time scales [21]. Furthermore, once an inner-loop subsystem is properly controlled, it can be considered to respond immediately to the reference. Hence, it is appropriate to reduce the fast dynamical subsystems by equivalent static model [18], [25].

The inductor, the chopper, and their control can be reduced to an equivalent conversion element. This equivalent element is considered without delay by assuming perfect response of the current control loop:

$$
\left\{\begin{array}{l}
u_{\mathrm{SC}} i_{\mathrm{SC}}=u_{\text {bat }} i_{\mathrm{ch} \mathrm{sc}} \eta_{\text {conv }}^{k_{\mathrm{conv}}} \\
i_{\mathrm{ch} \mathrm{sc}}=i_{\mathrm{ch} \mathrm{sc} \mathrm{ref}}
\end{array}\right.
$$

in which $\eta_{\text {conv }}$ is the efficiency of the DC/DC converter, $k_{\text {conv }}$ the coefficient depending on the power direction.

This reduced is organized by using Energetic Macroscopic Representation (EMR) (Fig. 2). EMR is a graphical formalism for control organization of energetic systems [27]. It has been widely used for control of electric and hybrid vehicles [28].

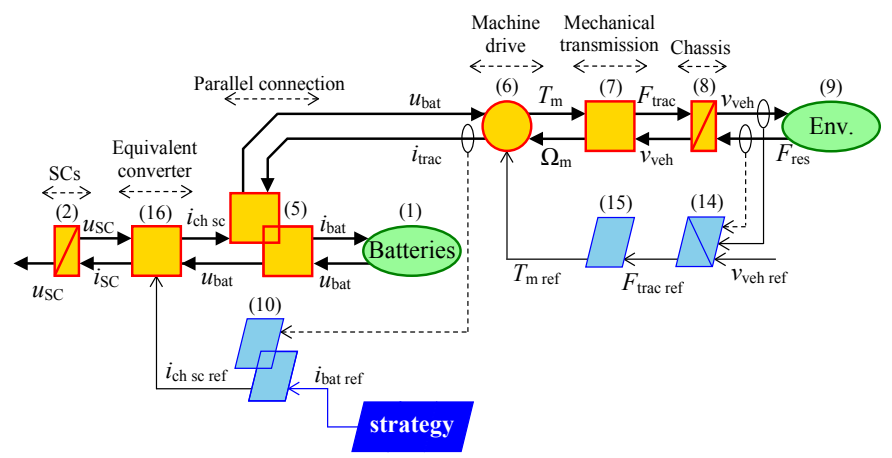

Fig. 2. Reduced EMR for energy management study.

\section{C.Filtering Strategy as a Traditional Rule-Based EMS}

Filtering strategy is developed based on the fact of different frequency characteristics of energy storages [10]. It can be realized by using a low-pass filter (LPF) as follows:

$$
i_{\text {bat ref }}=\frac{1}{\tau_{\mathrm{LPF}} s+1} i_{\text {trac meas }} ;
$$

where $\tau_{\text {LPF }}$ is the time constant of the LPF given by

$$
\tau_{\mathrm{LPF}}=\frac{1}{2 \pi f_{\mathrm{LPF}}} ;
$$

in which $f_{\mathrm{LPF}}$ is the cut-off frequency of the LPF. The frequency can be determined by considering Ragone plot [12], by adaptive studies [29], or by iterative examines [18].

\section{D. $\lambda$-control as an Adaptive PMP-based Strategy}

In this paper, for comparison purpose, the $\lambda$-control developed in [18] is addressed due to the same studied system configuration. In that work, the SCs energy is considered as 
the state variable for the reduced model. All the variables are then transformed into the batteries side. As a result, the obtained control law is conducted as follows:

$$
\left\{\begin{array}{l}
i_{\text {bat ref }}=\frac{\lambda \eta_{\mathrm{ch} \mathrm{sc}}^{k}\left(u_{\mathrm{bat} \mathrm{OC}}+r_{\mathrm{bat}} i_{\mathrm{trac} \text { meas }}\right)}{2\left(\lambda r_{\mathrm{bat}} u_{\mathrm{bat} \mathrm{OC}} \eta_{\mathrm{ch} \mathrm{sc}}^{k}-1\right)} \\
\lambda=\lambda_{0}+\Delta \lambda
\end{array} ;\right.
$$

where $\lambda$ is the co-state variable, $\lambda_{0}$ the initial co-state which is pre-computed by iterative simulations, $\Delta \lambda$ the adaptation. The adaptation is conducted by a classical PI controller to control the squared SCs voltage $u_{\mathrm{SC}}{ }^{2}$.

\section{E. Dynamic Programming as an Off-line Optimal Benchmark}

Thanks to the advantage of obtaining a global optimal solution, DP is used to deduce a benchmark for comparison. The method is based on solving the Bellman equation:

$$
J_{k, N}^{*}[x(k)]=\min _{u(k)}\left\{\begin{array}{l}
g_{D}[x(k), w(k)] \\
+J_{k+1, N}^{*}[f(x(k), w(k))]
\end{array}\right\} ;
$$

in which $J$ is the cost function to be minimized, $N$ the total number of time steps, $f$ the dynamical function of the system, $g_{D}$ the current accumulative cost, $x(k)$ and $w(k)$ the state and control variables at the $k^{\text {th }}$ step, respectively.

In the right-hand side, the term $g_{D}$ is the cost-to-go from the current $k^{\text {th }}$ step to the next $(k+1)^{\text {th }}$ step. The term $J_{k+1, N}{ }^{*}$ is the known-in-advance optimal cost-to-go from the $(k+1)^{\text {th }}$ step to the final step $N^{\text {th }}$. DP is therefore a backward method that can be computed off-line only.

\section{PROPOSED REAL-TIME STRATEGY}

\section{A. Problem Formulation}

\section{1) Mathematical System Dynamics}

To apply optimal control theory, the energy management problem should be formulated as an optimal control problem. For that, the system dynamical model serves as a set of equality constraints. The limitations of the state and control variables are inequality constraints.

In this work, the limitations are treated by the conventional method addressed in [18]. Thus, only the equality constraint, i.e. the dynamical model of the system, needs to be defined.

From the reduced representation (see Fig. 2), the reduced mathematical model of the system can be deduced as follows:

$$
\frac{d}{d t} u_{\mathrm{SC}}=-u_{\text {bat }} \frac{\eta_{\text {conv }}^{k}}{C_{\mathrm{SC}}} \frac{i_{\text {ch sc ref }}}{u_{\mathrm{SC}}} ;
$$

where $u_{\mathrm{SC}}$ is the state variable, $i_{\text {ch sc ref }}$ the control variable, $u_{\text {bat }}$ the disturbance input. Here, the resistance effect is neglected.

\section{2) Performance Criterion - Cost Function}

Since the objective is to reduce the batteries degradation, the rms value of its current is a relevant performance index:

$$
I_{\text {bat rms }}=\sqrt{\frac{1}{t_{\mathrm{f}}-t_{0}} \int_{t_{0}}^{t_{\mathrm{f}}} i_{\text {bat }}^{2} d t} ;
$$

in which $t_{0}$ and $t_{\mathrm{f}}$ are the initial and the final time, respectively.

Furthermore, quadratic functions are of interest for many optimization techniques [30]. Hence, the cost function of the studied energy management problem can be defined by:

$$
J=\int_{t_{\mathrm{o}}}^{t_{\mathrm{f}}} i_{\text {bat }}^{2} d t
$$

\section{B. Strategy Development Using PMP}

\section{1) Methodology}

First, the general background of PMP is briefly described. For a dynamical system

$$
\frac{d}{d t} x=f(x, w, t)
$$

where $x$ is the state variable and $w$ control variable; with the cost function given by

$$
J=h\left[x\left(t_{\mathrm{f}}\right), t_{\mathrm{f}}\right]+\int_{t_{\mathrm{o}}}^{t_{\mathrm{f}}} g(x, w, t) d t ;
$$

in which $h$ reflects the cost of final state $x\left(t_{\mathrm{f}}\right)$ and $g$ the integral cost of the progress; a Hamiltonian function can be defined by

$$
H=g(x, w, t)+\lambda f(x, w, t) ;
$$

where $\lambda$ is the co-state variable.

The PMP states that if a control law $w^{*}$ is optimal, it must satisfy the following three necessary conditions:

$$
\begin{gathered}
\frac{d}{d t} x^{*}=\frac{\partial H\left(x^{*}, w^{*}, \lambda^{*}, t\right)}{\partial \lambda} ; \\
\frac{d}{d t} \lambda^{*}=-\frac{\partial H\left(x^{*}, w^{*}, \lambda^{*}, t\right)}{\partial x} ; \\
H\left(x^{*}, w^{*}, \lambda^{*}, t\right) \leq H\left(x^{*}, w, \lambda^{*}, t\right) .
\end{gathered}
$$

Conditions (27) and (28) compose the dynamics of a Hamiltonian system. Condition (29) means the minimization of the Hamiltonian function. Conventional methods satisfy all conditions to obtain an off-line open-loop control law; an additional state feedback is then used for adaptation in realtime.

An alternative approach is proposed in [25]. Only condition (29) is used to directly deduce a real-time strategy. The Hamiltonian function contains a relationship between the control variable $i_{\text {ch sc ref }}$ and the state variable $u_{\mathrm{SC}}$. Hence, applying (29) by a partial derivative with respect to the control variable can eventually carry out an analytical closed-form strategy. The co-state variable $\lambda$ is then determined based on its physical meaning without considering the Hamiltonian system dynamics (27) and (28). The obtained strategy is indeed sub-optimal as the PMP theory is not strictly satisfied.

\section{2) Strategy Development}

From (21), assuming an ideal converter, the Hamiltonian is defined by:

$$
H=i_{\text {bat }}^{2}-\lambda \frac{u_{\text {bat }}}{C_{\mathrm{SC}}} \frac{i_{\text {ch sc ref }}}{u_{\mathrm{SC}}} .
$$

Condition (29) is realized by

$$
\frac{\partial H}{\partial i_{\text {ch sc ref }}}=0 \text {. }
$$

The calculation of the left-hand side of (31) is given from:

$$
i_{\text {bat }}=i_{\text {trac }}-i_{\text {ch sc }} \text {. }
$$

Besides, $i_{\text {trac }}$ is the disturbance without dependence on the control variable $i_{\text {ch sc ref. With assumption (16), that leads to }}$

$$
\frac{\partial\left(i_{\text {bat }}^{2}\right)}{\partial i_{\text {ch sc ref }}}=-2 i_{\text {bat }} \text {. }
$$

The partial derivative to be calculated therefore becomes 


$$
\frac{\partial H}{\partial i_{\text {ch sc ref }}}=-2 i_{\text {bat }}-\lambda \frac{u_{\text {bat }}}{C_{\mathrm{SC}}} \frac{i_{\text {ch sc ref }} \frac{\partial u_{\mathrm{SC}}}{\partial i_{\text {ch sc ref }}}-u_{\mathrm{SC}}}{u_{\mathrm{SC}}^{2}} .
$$

The partial derivative of $u_{\mathrm{SC}}$ with respect to $i_{\mathrm{ch} s \mathrm{ref}}$ is calculated by:

$$
\frac{\partial u_{\mathrm{SC}}}{\partial i_{\mathrm{ch} \mathrm{sc} \mathrm{ref}}}=\frac{1}{\frac{\partial\left(\frac{u_{\mathrm{SC}}}{u_{\text {bat }}} i_{\mathrm{SC}}\right)}{\partial u_{\mathrm{SC}}}}=\frac{1}{\frac{i_{\mathrm{SC}}}{u_{\text {bat }}}+\frac{u_{\mathrm{SC}}}{u_{\text {bat }}} \frac{\partial i_{\mathrm{SC}}}{\partial u_{\mathrm{SC}}}} .
$$

The partial derivative of $i_{\mathrm{SC}}$ with respect to $u_{\mathrm{SC}}$ is adopted from [24] as follows:

$$
\frac{\partial i_{\mathrm{SC}}}{\partial u_{\mathrm{SC}}}=-\frac{i_{\mathrm{SC}}}{\sqrt{u_{\mathrm{SC}}^{2}-4 r_{\mathrm{SC}} P_{\mathrm{SC}}}} .
$$

Applying (36) to (35), that leads to:

$$
\frac{\partial u_{\mathrm{SC}}}{\partial i_{\mathrm{ch} \mathrm{sc} \text { ref }}}=\frac{u_{\mathrm{bat}} \sqrt{u_{\mathrm{SC}}^{2}-4 r_{\mathrm{SC}} P_{\mathrm{SC}}}}{i_{\mathrm{SC}} \sqrt{u_{\mathrm{SC}}^{2}-4 r_{\mathrm{SC}} P_{\mathrm{SC}}}-P_{\mathrm{SC}}} .
$$

The partial derivative of the Hamiltonian is then carried out:

$$
\begin{aligned}
& \frac{\partial H}{\partial i_{\text {ch sc ref }}}=-2 i_{\text {bat }} \\
& -\lambda \frac{u_{\text {bat }}}{C_{\mathrm{SC}}} \frac{i_{\text {ch scef }} \frac{u_{\text {bat }} \sqrt{u_{\mathrm{SC}}^{2}-4 r_{\mathrm{SC}} P_{\mathrm{SC}}}}{i_{\mathrm{SC}} \sqrt{u_{\mathrm{SC}}^{2}-4 r_{\mathrm{SC}} P_{\mathrm{SC}}}-P_{\mathrm{SC}}}-u_{\mathrm{SC}}}{u_{\mathrm{SC}}^{2}} .
\end{aligned}
$$

By applying (31) to (38), the SCs chopper current reference can be deduced as a function of the measured variables $u_{\mathrm{SC}}$, $i_{\mathrm{SC}}, u_{\text {bat }}$, and $i_{\text {bat }}$ as follows:

$$
i_{\text {ch sc ref }}=i_{\text {ch sc ref }}\left(u_{\mathrm{SC}}, i_{\mathrm{SC}}, u_{\text {bat }}, i_{\text {bat }}\right) .
$$

However, considering the control scheme of Fig. 2, the strategy delivers the batteries current reference $i_{\text {bat ref. }}$ Then, $i_{\text {ch sc ref }}$ is obtained by compensation of the measured traction current as in (10). Thus, the control law should be:

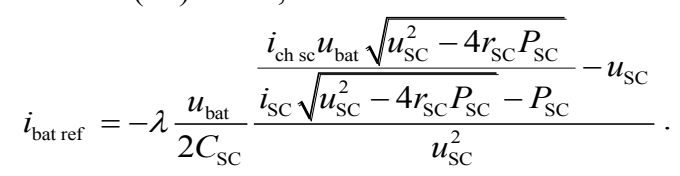

Considering that

$$
\frac{i_{\mathrm{ch} \mathrm{sc}}}{i_{\mathrm{SC}}}=\frac{u_{\mathrm{SC}}}{u_{\text {bat }}}
$$

By assuming the ideal conversion, (40) can be expressed by

$$
i_{\text {bat ref }}=\lambda \frac{u_{\text {bat }}}{2 C_{\mathrm{SC}}} \frac{u_{\mathrm{SC}}-\frac{u_{\mathrm{SC}} \sqrt{u_{\mathrm{SC}}^{2}-4 r_{\mathrm{SC}} u_{\mathrm{SC}} i_{\mathrm{SC}}}}{\sqrt{u_{\mathrm{SC}}^{2}-4 r_{\mathrm{SC}} u_{\mathrm{SC}} i_{\mathrm{SC}}}-u_{\mathrm{SC}} i_{\mathrm{SC}}}}{u_{\mathrm{SC}}^{2}} .
$$

Once the co-state variable $\lambda$ is determined, (42) will be ready to serve as a real-time strategy.

\section{3) Co-state Variable $\lambda$ Physical Meaning and Determination}

This approach determines $\lambda$ not by the Hamiltonian dynamics (27) and (28), but by its physical meaning.

The physical essence of the co-state variable has been pointed out in the literature [31]. It is an equivalent factor to convert the dynamical function of the system to an equivalent cost to be minimized. Such a physical explanation has been also figured out by previous works, e.g. [24]. It is used here to calculate $\lambda$.
From the Hamiltonian (30), whereas the cost term $i_{\text {bat }}{ }^{2}$ has a dimension of Ampere squared, the dimension of the dynamics term is Ampere per Farad. To perform a proper subtraction, the co-state variable, as an equivalent factor, should have a form of $\lambda=$ Capacitance $\times$ Current. On the right-hand side, the former term can be chosen as the SCs capacitance which is the only capacitive quantity of the studied system.

The latter term of current is more flexible to be determined. In the previous work [25], it is given by the expected maximal batteries current when the SCs can no longer support the batteries. This value is set by the proportions of the batteries C-rate regarding the driving modes. This approach leads to a high-performance strategy validated by the reported simulation results. However, C-rate is an indicator of batteries energy rather than their power. The justification of this approach is therefore not so convinced.

To overcome the issue mentioned above, $\lambda$ is determined from the traction rms current:

$$
\lambda=C_{\mathrm{SC}} i_{\text {trac rms }} \text {; }
$$

in which, $i_{\text {trac rms }}$ depends on the driving modes and should be pre-calculated. The pre-calculation can be done with a standard driving cycle. In this work, the Worldwide harmonized Light duty driving Test Cycle (WLTC) is used. Based on the studied vehicle, the WLTC class 2 (Fig. 3) is used for the pre-calculation of the $i_{\text {trac rms. }}$.

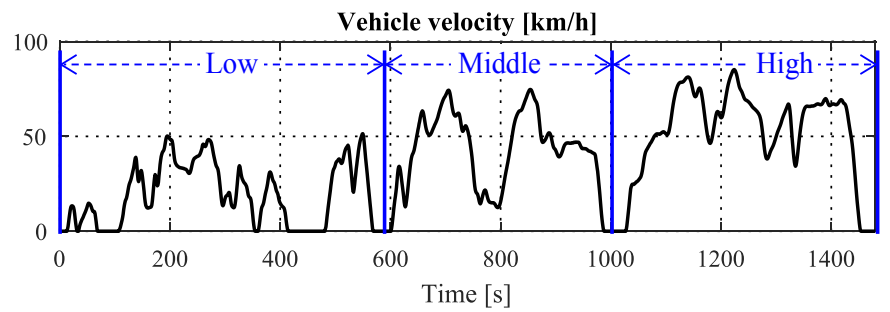

Fig. 3. WLTC class 2 used for co-state variable $\lambda$ determination.

\section{4) Strategy Implementation}

The strategy is in an analytical form with simple mathematical calculations. It is therefore easy to be implemented in real-time (Fig. 4). Three sensors are required for the measurements of the SCs voltage $u_{\mathrm{SC}}$, batteries voltage $u_{\text {bat, }}$ and SCs current $i_{\mathrm{SC}}$ to compute the control variable $i_{\text {bat ref cal }}$ from (42) and (43). A supplementary sensor for $i_{\text {trac }}$ is used only when the SCs voltage reaches limitations. In this case, the $i_{\text {bat ref }}$ is switched from $i_{\text {bat ref cal }}$ to the $i_{\text {trac meas }}$.

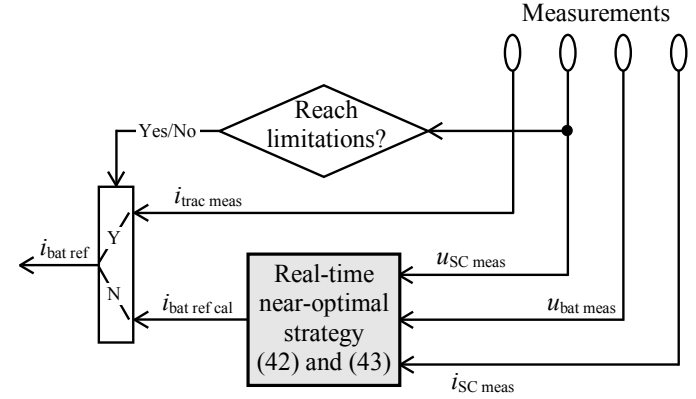

Fig. 4. Implementation of the proposed EMS. 


\section{Comparative Evaluation by Simulation}

\section{A. Simulation Conditions}

The reference vehicle is Tazzari Zero (main parameters in Table II). This EV is originally supplied by a battery pack of Lithium-iron phosphate LiFePO4 (LFP) cells. The battery has been sized for a real driving range around $100 \mathrm{~km}$. For studies of H-ESSs, it is modified to the semi-active configuration by adding a SC subsystem. SC and battery size are constant during the study to fairly compare the different EMS strategies.

Three standard driving cycles are considered for testing:

- WLTC class 2, which is utilized to determine the co-state variable $\lambda$, with urban, rural, and highway parts. This is the result of a statistical study that addressed various standard and real-world driving cycles from countries in Europe, Asia, and America [32].

- NEDC with urban and highway parts. This driving cycle is commonly used in many studies because it can examine clearly the acceleration and deceleration behaviors of vehicles. This cycle is however too smooth in comparison with the real-world-based cycles.

- ARTEMIS urban which is an urban cycle. This cycle addresses better than NEDC the fluctuations especially in urban areas.

Moreover, a real-world driving cycle was recorded through driving around the campus of University of Lille. It can be considered as a rural cycle.

The evaluation criterion is the batteries rms current; the lower the $i_{\text {bat rms }}$ is, the better the battery life-time is. It is because the rms current cause self-heating in batteries due to Joule losses in their internal resistance. Whereas the degradation of the batteries increases with the rise of temperature [33], [34]. Five cases are compared: (i) conventional EV with battery only, (ii) filtering strategy as a popular rule-based EMS, (iii) $\lambda$-control as an adaptive PMPbased EMS, (iv) the proposed sub-optimal strategy, and (v) DP as an optimal benchmark.

Considering a previous work in the field [18], this comparison uses the cut-off frequency $f_{\mathrm{LPF}}=48 \mathrm{mHz}$ and the same $\lambda$-control parameters for adaptive PMP-based EMS. The simulations are carried out in $\mathrm{MATLAB}^{\circledR} /$ Simulink $^{\circledR}$.

TABLE II

FULL-SCALE SYSTEM PARAMETERS

\begin{tabular}{|c|c|c|}
\hline Parameters & & Values \\
\hline \multicolumn{3}{|c|}{ Vehicle (Tazzari Zero) } \\
\hline Vehicle total mass & $M_{\mathrm{veh}}$ & $692 \mathrm{~kg}$ \\
\hline Aerodynamic standard & $c_{x} A$ & $0.7 \mathrm{~m}^{2}$ \\
\hline Rolling coefficient & $k_{\text {roll }}$ & 0.02 \\
\hline Air density (at $20^{\circ} \mathrm{C}$ ) & $\rho$ & $1.223 \mathrm{~kg} / \mathrm{m}^{3}$ \\
\hline \multicolumn{3}{|c|}{ Electrical machine (induction machine) } \\
\hline Maximal power & $P_{\mathrm{m} \max }$ & $15 \mathrm{~kW}$ \\
\hline Nominal efficiency & $\eta_{\mathrm{m} \mathrm{nom}}$ & $85 \%$ \\
\hline \multicolumn{3}{|c|}{ Batteries (Thunder Sky TS-LFP160AHA cells) } \\
\hline Battery bank capacitance & $C_{\text {bat }}$ & $160 \mathrm{Ah}$ \\
\hline Battery bank resistance (at $80 \%$ SoC) & $r_{\text {bat }}$ & $28 \mathrm{~m} \Omega$ \\
\hline Battery bank OCV (at $80 \%$ SoC) & $u_{\text {bat OC }}$ & $78 \mathrm{~V}$ \\
\hline \multicolumn{3}{|c|}{ SCs subsystem (Maxwell BMOD0165 P048 BXX module) } \\
\hline Inductor inductance & $L$ & $0.2 \mathrm{mH}$ \\
\hline Inductor parasitic resistance & $r_{\mathrm{L}}$ & $10.0 \mathrm{~m} \Omega$ \\
\hline $\mathrm{SC}$ internal resistance & $r_{\mathrm{SC}}$ & $6.3 \mathrm{~m} \Omega$ \\
\hline SC nominal voltage & $u_{\mathrm{SC} \text { nom }}$ & $48 \mathrm{~V}$ \\
\hline SC nominal capacitance & $C_{\mathrm{SC}}$ & $165 \mathrm{~F}$ \\
\hline
\end{tabular}

\section{B. Results and Discussions}

Simulation results for comparative evaluation are reported in Fig. 5. The pure battery EV always leads to the highest battery rms current; meanwhile, the DP offers the lowest $i_{\text {bat rms }}$ thanks to its optimal solution.

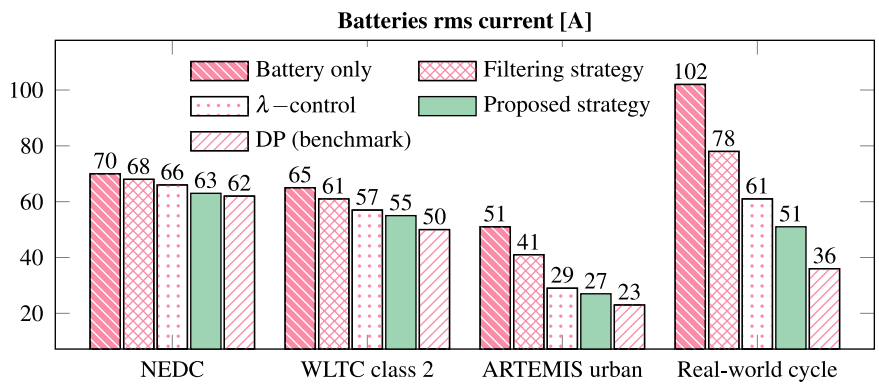

Fig. 5. Comparative evaluation of the studied EMSs.

The H-ESS has significant effectiveness with the highly fluctuated driving conditions such as ARTEMIS urban and especially the studied real-world cycle. For the last one, the proposed strategy can reduce up to $50 \%$ of the batteries rms current that means life-time extension.

In the less fluctuating cycles like NEDC and WLTC, the HESS has a lower impact. In the case of NEDC, the ideal solution from DP can only save $11.4 \%$ of the $i_{\text {bat rms; }}$; whereas it is $10 \%$ by using the proposed real-time strategy. H-ESS seems more suitable for city cars than for the other sorts of vehicles working with smoother conditions.

The most important is that the proposed EMS leads to the best results for any tested cycle.

\section{V.EXPERIMENTAL VALIDATION OF THE PROPOSED STRATEGY}

\section{A. Experimental Setup}

Experimental validations are carried out by using reducedscale power hardware-in-the-loop (HIL) simulation. This study focuses on the energy management strategy of the battery/SC H-ESS. The traction subsystem therefore plays the role of generating the traction current which is the disturbance of the studied system. Thus, the traction subsystem, including the vehicle dynamics, can be emulated by using a controllable current source. Similarly, a controllable voltage source is used to emulate the batteries.

Fig. 6 illustrates the principle of the reduced-scale power HIL simulation used in this work. The traction model, including the vehicle inertia, generates the traction current reference. Via the power adaptation block, this reference is imposed to the reduced-scale experimental test bench. If the current of the emulator follows the generated reference, the emulator can emulate well the traction dynamics. It is similar for the batteries emulation.

Voltage and currents controllers are realized by using the classical PI controllers. The models and the controllers are implemented in the controller board (dSPACE DS1103). The current and voltage sources for emulations are realized by using SCs, inductors, a DC bus capacitor, and power electronics bidirectional choppers (see Fig. 7). The SCs are used to emulate the batteries and the traction subsystems thanks to their fast dynamics. It is noteworthy that the 
dynamics of the components used for emulation should be faster than that of the emulated system. The experimental setup is shown in Fig. 8. Main parameters of the components are given in Table III.

The voltages and the currents of all the SC banks and the emulated batteries voltage (on the capacitor $C_{\text {bat emu }}$ ) are measured by sensors. The currents $i_{\mathrm{bat}} \mathrm{HIL}, i_{\text {trac HIL }}$, and $i_{\mathrm{ch} \mathrm{sc} \mathrm{HIL}}$ cannot be directly measured because they are pulses as a result of choppers switching. They are estimated by using the corresponding measured $\mathrm{SC}$ currents $i_{\mathrm{SC} \text { bat }}, i_{\mathrm{SC} \text { trac }}$, and $i_{\mathrm{SC}}$. The estimation is obtained by using the average conversion relationship of the choppers (similar to (4)).

The power and the energy of the studied system are scaled down by a reduction ratio for power HIL implementation [35]. The adaptation ratio is determined regarding the power and energy limitation of the available power components. It must ensure that the SCs used for traction emulation can absorb all the energy delivered by the SCs for the batteries emulation. The required energy storage capabilities are calculated with the WLTC, which is the longest driving cycle under study. Regarding that, the adaptation ratio is set to 35 .

The emulated batteries voltage is equal to that voltage of the full-scale system. Thus, the currents $i_{\text {trac }}, i_{\text {bat }}$, and $i_{\text {ch sc }}$ are scaled down exactly by the power ratio.

It is slightly more complicated for scaling the $\mathrm{SC}$ voltage. The SC energy must be scaled down by the same reduction ratio as that of the power. The simplest way is to reduce the SC capacitance by that ratio. The SC voltage range can be therefore remained as in the full-scale system. Unfortunately, the SC pack available in the laboratory has higher capacitance than it should do. Thus, the SC voltage range must be reduced. The upper boundary $u_{\mathrm{SC} \text { max }}$ are set the same for both full-scale simulations and reduced-scale experiments. But the lower boundary $u_{\mathrm{SC} \text { min }}$ of the reduced-scale system is higher than that of the full-scale system.

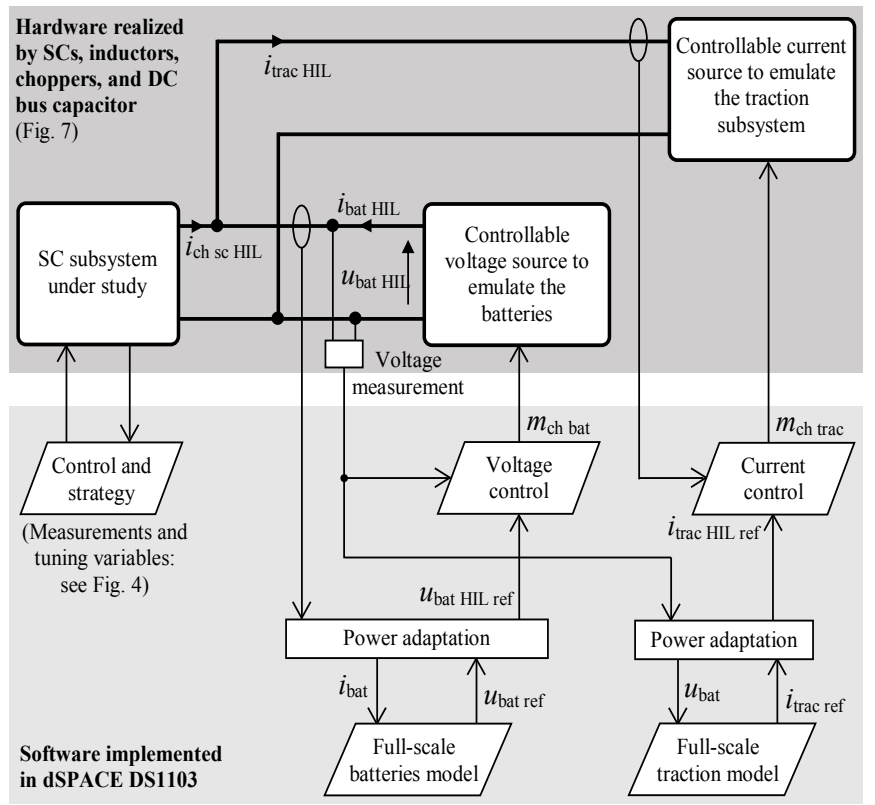

Fig. 6. Reduced-scale power HIL system for experimental validation.

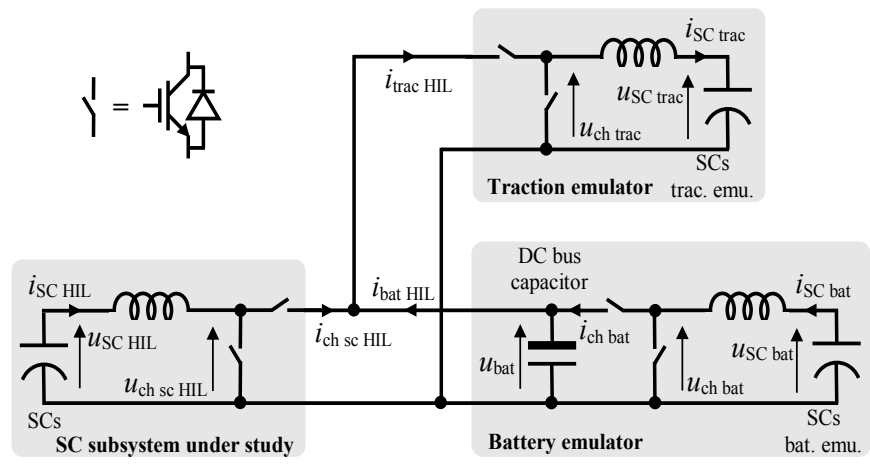

Fig. 7. Experimental system hardware configuration.

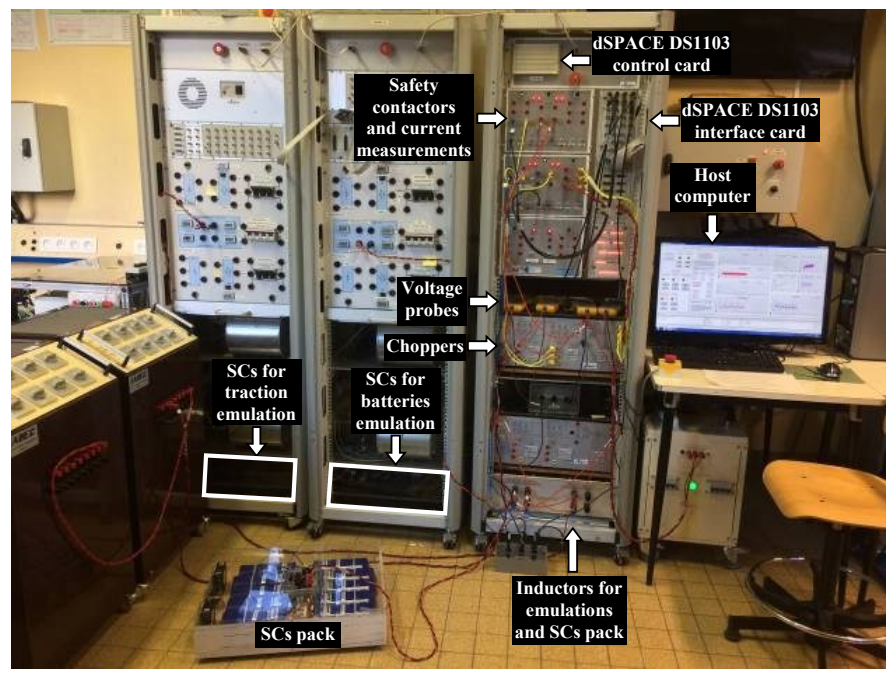

Fig. 8. Experimental test bench.

TABLE III

REDUCED-SCALE POWER HIL SYSTEM PARAMETERS

\begin{tabular}{|c|c|c|}
\hline Parameters & & Values \\
\hline Adaptation ratio & & 35 \\
\hline \multicolumn{3}{|c|}{ SCs for battery and traction emulators } \\
\hline SC capacitance & $C_{\mathrm{SC} \text { battrac }}$ & $130 \mathrm{~F}$ \\
\hline SC nominal voltage & $u_{\mathrm{SC} \text { bat/trac nom }}$ & $54 \mathrm{~V}$ \\
\hline \multicolumn{3}{|c|}{ SC subsystem } \\
\hline SC capacitance & $C_{\mathrm{SC}}$ & $14.5 \mathrm{~F}$ \\
\hline SC nominal voltage & $u_{\mathrm{SC} \text { nom }}$ & $60 \mathrm{~V}$ \\
\hline SC internal resistance & $r_{\mathrm{SC}}$ & $73.0 \mathrm{~m} \Omega$ \\
\hline \multicolumn{3}{|c|}{ Inductor of the battery emulator } \\
\hline Inductor inductance & $L_{\text {bat emu }}$ & $0.758 \mathrm{mH}$ \\
\hline Inductor parasitic resistance & $r_{\text {L bat emu }}$ & $0.20 \Omega$ \\
\hline \multicolumn{3}{|c|}{ Inductor of the traction emulator } \\
\hline Inductor inductance & $L_{\text {trac emu }}$ & $0.752 \mathrm{mH}$ \\
\hline Inductor parasitic resistance & $r_{\text {L trac emu }}$ & $0.20 \Omega$ \\
\hline \multicolumn{3}{|c|}{ Inductor } \\
\hline Inductor inductance & $L$ & $0.751 \mathrm{mH}$ \\
\hline Inductor parasitic resistance & $r_{\mathrm{L}}$ & $0.18 \Omega$ \\
\hline \multicolumn{3}{|c|}{ Capacitor of the battery emulator } \\
\hline Capacitor capacitance & $C_{\text {bat emu }}$ & $2200 \mathrm{uF}$ \\
\hline
\end{tabular}




\section{B. Results and Discussions}

To validate the real-time performances of the proposed strategy, the real-world driving cycle is under study (Fig. 9).

The vehicle velocity of the studied driving cycle is imposed (Fig. 9). The simulation results of the full-scale studied vehicle present the evolutions of the batteries voltage, the SCs voltage, and the H-ESS currents (Fig. 10). The experimental results of the reduced-scale power HIL system present the corresponding evolutions (Fig. 11).

Regarding the power and energy reductions, it can be pointed out that the experimental results match simulation results. There is only a very small difference in the SCs voltage $u_{\mathrm{SC}}$. It is due to the difference between the internal resistance of the reduced-scale SC (see Table III) and that of the full-scale SC (see Table II). The fine-matched results verify the ability of the reduced-scale power HIL simulation in examining the real-time performances of the EMS.

The driving condition of the studied real-world cycle fluctuates very much; that is suitable for SCs. That is why they can perfectly protect the batteries from peak currents required by the traction subsystem. A reduction of about $70 \%$ of the batteries peak currents is reported in comparison to the demanded traction current.

The accuracy of the emulations can be estimated by

$$
\varepsilon=\frac{\int_{0}^{T_{\mathrm{cyc}}}\left|x-x_{\mathrm{ref}}\right| d t}{\int_{0}^{T_{\mathrm{cyc}}}|x| d t}
$$

where $x$ generally denotes $i_{\text {trac }}$ and $u_{\text {bat }}$. The relative errors (see Table IV) are very small that confirms the controlled current and voltage sources can emulate well the traction subsystem and the batteries, respectively.

Table IV also gives quantitative results to verify the performance of the proposed EMS in comparison between the full-scale off-line simulation and the reduced-scale HIL simulation. The batteries rms currents are reduced in comparison with the traction ones thanks to the H-ESS managed by the proposed strategy. The reductions are $49.6 \%$ and $49.8 \%$ for full-scale and reduced-scale systems, respectively. That verifies the reduced-scale HIL system examines exactly the behaviors of the full-scale studied system.

TABLE IV

EMULATION SYSTEM PERFORMANCE

\begin{tabular}{lcc}
\hline \hline & \multicolumn{3}{c}{ Accuracy } \\
\hline \multirow{2}{*}{$\begin{array}{c}\text { Error of response } \\
\text { to reference }(\varepsilon)\end{array}$} & $i_{\text {trac HIL }}$ & $u_{\text {bat HIL }}$ \\
\cline { 2 - 3 } & $0.80 \%$ & $0.13 \%$ \\
\hline \multirow{2}{*}{ The rms currents } \\
\hline \multirow{2}{*}{ Reduced-scale } & $i_{\text {trac rms }[\mathrm{A}]}$ & $i_{\text {bat rms }[\mathrm{A}]}$ \\
\cline { 2 - 3 } & 102.0 & 51.4 \\
\cline { 2 - 3 } & $i_{\text {trac HIL rms }[\mathrm{A}]}$ & $i_{\text {bat HIL rms }[\mathrm{A}]}$ \\
\hline \hline
\end{tabular}

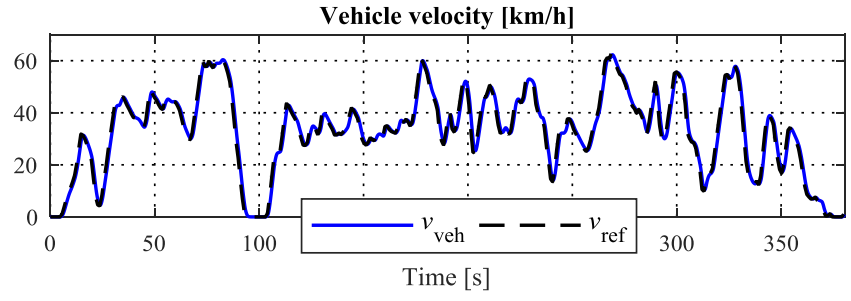

Fig. 9. Velocity of the studied real-world driving cycle.
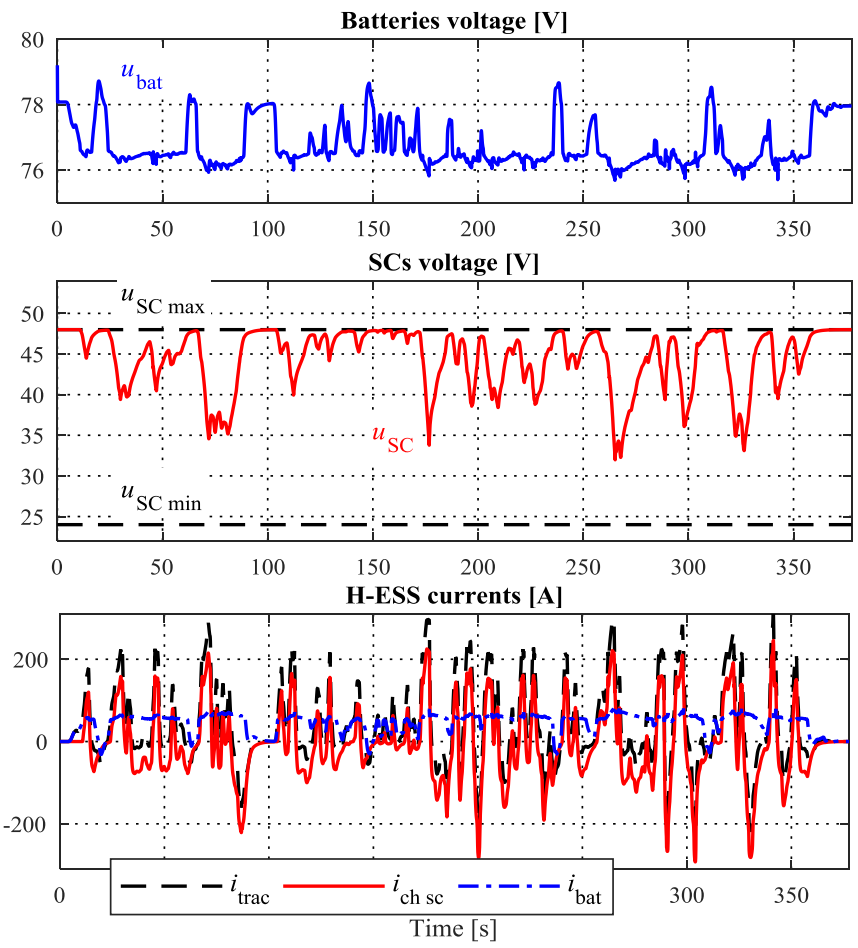

Fig. 10. Simulation results of the full-scale vehicle.
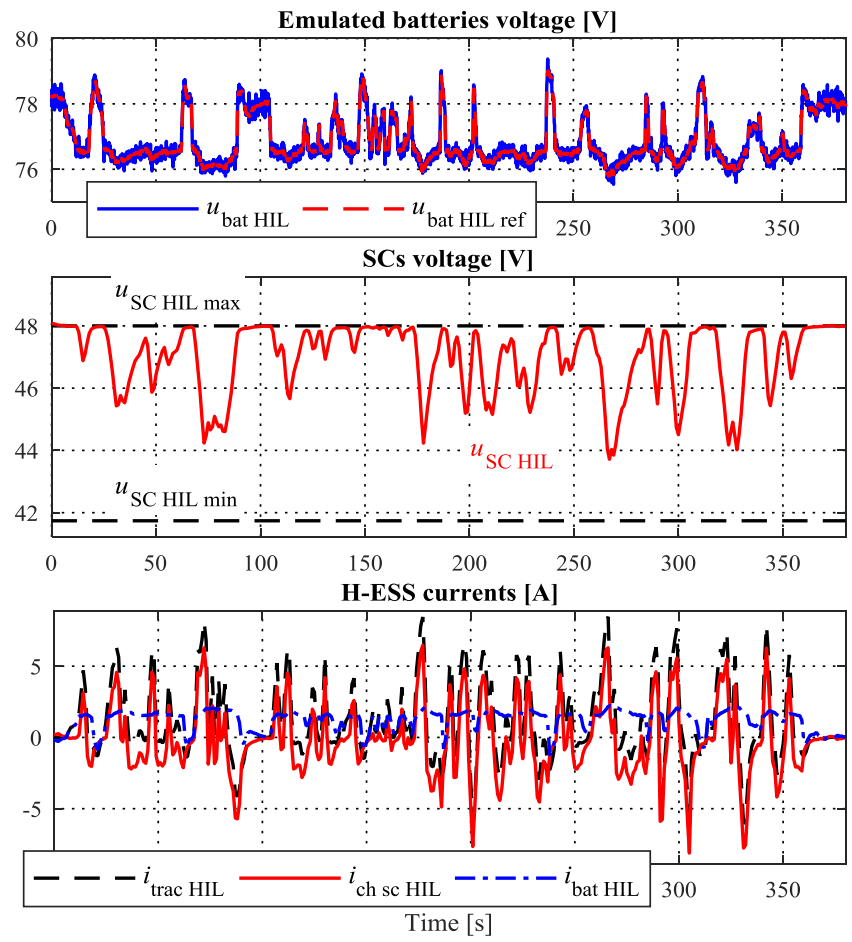

Fig. 11. Experimental results of the reduced-scale power HIL system. 


\section{CONCLUSION}

This paper proposes and validates a new approach of using PMP to develop real-time EMS for H-ESSs in EVs. By using only, the third necessary condition of PMP, a closed-form solution containing the state variable can be deduced. Thus, no additional adaptation of the co-state variable is required for real-time applications.

This novel strategy has been compared to the conventional EMSs including filtering, $\lambda$-control, and DP. Simulation results have figured out that the proposed EMS gives the highest benefit in term of batteries rms current reduction. By comparing to the off-line optimal benchmark given by DP, the EMS has been verified to be close-to-optimal. Moreover, the real-time performances of the proposed strategy have been demonstrated by reduced-scale power HIL experiments.

\section{REFERENCES}

[1] S. F. Tie and C. W. Tan, "A review of energy sources and energy management system in electric vehicles," Renew. Sustain. Energy Rev., vol. 20, pp. 82-102, 2013.

[2] F. R. Salmasi, "Control strategies for hybrid electric vehicles: Evolution, classification, comparison, and future trends," IEEE Trans. Veh. Technol., vol. 56, no. 5, pp. 2393-2404, 2007.

[3] S. G. Wirasingha and A. Emadi, "Classification and review of control strategies for plug-in hybrid electric vehicles," IEEE Trans. Veh. Technol., vol. 60, no. 1, pp. 111-122, 2011.

[4] M. Zandi, A. Payman, J. P. Martin, S. Pierfederici, B. Davat, and F. Meibody-Tabar, "Energy management of a fuel cell/supercapacitor/battery power source for electric vehicular applications," IEEE Trans. Veh. Technol., vol. 60, no. 2, pp. 433-443, 2011.

[5] J. Talla, L. Streit, Z. Peroutka, and P. Drabek, "Position-Based T-S Fuzzy Power Management for Tram With Energy Storage System," IEEE Trans. Ind. Electron., vol. 62, no. 5, pp. 3061-3071, 2015.

[6] L. Wang, E. G. Collins, and H. Li, "Optimal design and real-time control for energy management in electric vehicles," IEEE Trans. Veh. Technol., vol. 60 , no. 4, pp. 1419-1429, 2011.

[7] R. Carter, A. Cruden, and P. J. Hall, "Optimizing for efficiency or battery life in a battery/supercapacitor electric vehicle," IEEE Trans. Veh. Technol., vol. 61, no. 4, pp. 1526-1533, 2012.

[8] J. Armenta, C. Núñez, N. Visairo, and I. Lázaro, "An advanced energy management system for controlling the ultracapacitor discharge and improving the electric vehicle range," J. Power Sources, vol. 284, pp. 452-458, 2015.

[9] F. Machado, J. P. Trovão, and C. H. Antunes, "Effectiveness of Supercapacitors in Pure Electric Vehicle Using a Hybrid Meta-Heuristic Approach," IEEE Trans. Veh. Technol., vol. 65, no. 1, pp. 29-36, 2016.

[10] P. Thounthong and S. Rael, "The benefits of hybridization," IEEE Ind. Electron. Mag., vol. 3, no. 3, pp. 25-37, 2009.

[11] E. Schaltz, A. Khaligh, and P. O. Rasmussen, "Influence of battery/ultracapacitor energy-storage sizing on battery lifetime in a fuel cell hybrid electric vehicle," IEEE Trans. Veh. Technol., vol. 58, no. 8, pp. 3882-3891, 2009.

[12] A.-L. Allègre, R. Trigui, and A. Bouscayrol, "Flexible real-time control of a hybrid energy storage system for electric vehicles," IET Electr. Syst. Transp., vol. 3, no. 3, pp. 79-85, 2013.

[13] Z. Song, H. Hofmann, J. Li, J. Hou, X. Han, and M. Ouyang, "Energy management strategies comparison for electric vehicles with hybrid energy storage system," Appl. Energy, vol. 134, pp. 321-331, 2014.

[14] M. Koot, J. T. B. A. Kessels, B. de Jager, W. P. M. H. Heemels, P. P. J. van den Bosch, and M. Steinbuch, "Energy Management Strategies for Vehicular Electric Power Systems," IEEE Trans. Veh. Technol., vol. 54, no. 3, pp. 771-782, 2005.

[15] S. Delprat, J. Lauber, T.-M. Guerra, and J. Rimaux, "Control of a parallel hybrid powertrain: optimal control," IEEE Trans. Veh. Technol., vol. 53, no. 3, pp. 872-881, 2004.

[16] T. Li, H. Liu, D. Zhao, and L. Wang, "Design and analysis of a fuel cell supercapacitor hybrid construction vehicle," Int. J. Hydrogen Energy, vol. 41, pp. 12307-12319, 2016.
[17] Z. Chen, C. C. Mi, B. Xia, and C. You, "Energy management of powersplit plug-in hybrid electric vehicles based on simulated annealing and Pontryagin's minimum principle," J. Power Sources, vol. 272, pp. 160$168,2014$.

[18] A. Castaings, W. Lhomme, R. Trigui, and A. Bouscayrol, "Comparison of energy management strategies of a battery/supercapacitors system for electric vehicle under real-time constraints," Appl. Energy, vol. 163, pp. 190-200, 2016.

[19] X. Hu, L. Johannesson, N. Murgovski, and B. Egardt, "Longevityconscious dimensioning and power management of the hybrid energy storage system in a fuel cell hybrid electric bus," Appl. Energy, vol. 137, pp. 913-924, 2015.

[20] O. Gomozov, J. P. Trovão, X. Kestelyn, M. Dubois, P. F. Trov, and X. Kestelyn, "Adaptive Energy Management System Based on a Real-Time Model Predictive Control with Non-Uniform Sampling Time for Multiple Energy Storage Electric Vehicle," IEEE Trans. Veh. Technol., vol. 66, no. 7, pp. 5520-5530, 2017.

[21] J. P. Trovão, P. G. Pereirinha, H. M. Jorge, and C. H. Antunes, "A multi-level energy management system for multi-source electric vehicles - An integrated rule-based meta-heuristic approach," Appl. Energy, vol. 105, pp. 304-318, 2013.

[22] J. T. B. A. Kessels, M. W. T. Koot, P. P. J. van den Bosch, and D. B. Kok, "Online Energy Management for Hybrid Electric Vehicles," IEEE Trans. Veh. Technol., vol. 57, no. 6, pp. 3428-3440, 2008.

[23] S. Kermani, R. Trigui, S. Delprat, B. Jeanneret, and T. M. Guerra, "PHIL implementation of energy management optimization for a parallel HEV on a predefined route," IEEE Trans. Veh. Technol., vol. 60, no. 3, pp. 782-792, 2011.

[24] A. Nguyen, J. Lauber, and M. Dambrine, "Optimal control based algorithms for energy management of automotive power systems with battery/supercapacitor storage devices," Energy Convers. Manag., vol. 87, pp. 410-420, 2014.

[25] B.-H. Nguyễn, J. P. Trovão, R. German, and A. Bouscayrol, "An Optimal Control-Based Strategy for Energy Management of Electric Vehicles using Battery/Supercapacitor," in The 14th IEEE Vehicle Power and Propulsion Conference (VPPC'17), 2017.

[26] C. Dépature, W. Lhomme, A. Bouscayrol, L. Boulon, P. Sicard, and T. Jokela, "Characterisation of the electric drive of EV: on-road versus offroad method," IET Electr. Syst. Transp., vol. 7, no. 3, pp. 215-222, 2017.

[27] A. Bouscayrol, J. P. Hautier, and B. Lemaire-Semail, "Graphic Formalisms for the Control of Multi-Physical Energetic Systems: COG and EMR," in Systemic Design Methodologies for Electrical Energy Systems: Analysis, Synthesis and Management, X. Roboam, Ed. ISTE Ltd, 2013, pp. 89-124.

[28] W. Lhomme, A. Bouscayrol, S. Syed, S. Roy, F. Gailly, and O. Pape, "Energy Savings of a Hybrid Truck using a Ravigneaux Gear Train," IEEE Trans. Veh. Technol., vol. 66, no. 10, pp. 1-1, 2017.

[29] A. Florescu, S. Bacha, I. Munteanu, A. I. Bratcu, and A. Rumeau, "Adaptive frequency-separation-based energy management system for electric vehicles," J. Power Sources, vol. 280, pp. 410-421, 2015.

[30] A. E. Bryson and Y.-C. Ho, Applied Optimal Control: Optimization, Estimation, and Control. John Wiley \& Sons, 1975.

[31] I. M. Ross, A Primer on Pontryagin's Principle in Optimal Control, Second. Collegiate Publishers, 2015.

[32] M. Tutuianu et al., "Development of a World-wide Worldwide harmonized Light duty driving Test Cycle (WLTC)," 2014.

[33] I. Baghdadi, O. Briat, J. Y. Delétage, P. Gyan, and J. M. Vinassa, "Lithium battery aging model based on Dakin's degradation approach," J. Power Sources, vol. 325, pp. 273-285, 2016.

[34] T. Waldmann, M. Wilka, M. Kasper, M. Fleischhammer, and M. Wohlfahrt-Mehrens, "Temperature dependent ageing mechanisms in Lithium-ion batteries - A Post-Mortem study," J. Power Sources, vol. 262, pp. 129-135, 2014.

[35] A. L. Allègre, A. Bouscayrol, J. N. Verhille, P. Delarue, E. Chattot, and S. El-Fassi, "Reduced-scale-power hardware-in-the-loop simulation of an innovative subway," IEEE Trans. Ind. Electron., vol. 57, no. 4, pp. $1175-1185,2010$. 


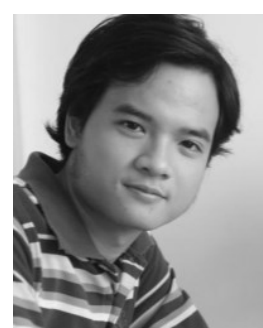

Bảo-Huy Nguyễn received his B.S. and M.S. degrees in electrical engineering from Hanoi University of Science and Technology, Hanoi, Vietnam, in 2010 and 2015, respectively. He is currently working toward the Ph.D. in the L2EP, Université de Lille, France and the e-TESC Lab., Université de Sherbrooke, QC, Canada, within a France-Québec collaboration program.

Since 2013, he has been a Research Associate at the Centre for Technology Innovation, Hanoi University of Science and Technology, Hanoi, Vietnam. His research interests include control engineering, power electronics, machine drives, graphical formalism, and their applications for electric and hybrid vehicles.

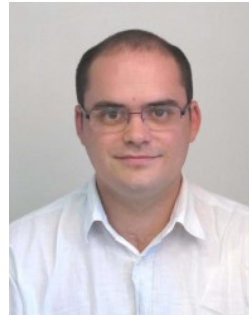

Ronan German was born in Roanne, France, in 1986. He received a Ph.D. degree in Electrical Engineering at University of Lyon in 2013. From 2013 to 2015 he was an assistant professor at the University of Lyon for two years. Since September 2015 he became an associate professor at the University of Lille in the Laboratory of Electrical Engineering and Power electronics (L2EP). His current research interests include the management of energy storage systems in the context of electric vehicles as a function of various parameters.

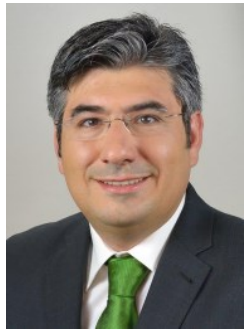

João Pedro F. Trovão (S'08, M'13, SM'17) was born in Coimbra, Portugal, in 1975. He received the M.Sc. degree and the Ph.D. degree in Electrical Engineering from the University of Coimbra, Coimbra, Portugal, in 2004 and 2013, respectively. From 2000 to 2014, he was a Teaching Assistant and an Assistant Professor with the Polytechnic Institute of Coimbra-Coimbra Institute of Engineering (IPCISEC), Portugal. Since 2014, he has been a Professor with the Department of Electrical Engineering and Computer Engineering, University of Sherbrooke, Sherbrooke, QC, Canada, where he holds the Canadian Research Chair position in Efficient Electric Vehicles with Hybridized Energy Storage Systems. His research interests cover the areas of electric vehicles, hybridized energy storage systems, energy management and rotating electrical machines. J. P. F. Trovão was the General Chair of the 2018 IEEE Vehicle Power and Propulsion Conference, as well as the Technical Program Committee Co-Chair of the 2017 IEEE Vehicle Power and Propulsion Conference. He was the General Co-Chair and the Technical Program Committee Co-Chair of the 2014 IEEE Vehicle Power and Propulsion Conference, as well as the Award Committee Member for the 2015 and 2016 IEEE Vehicle Power and Propulsion Conferences. He was a Guest Editor for the Special Issue of IET ELECTRICAL SySTEMS IN TRANSPORTATION ON ENERgY STORAGE AND EleCtriC POWER SubSystems For Advanced Vehicles. He was a Guest Editor for the Special Issue of IEEE TRANSACTIONS ON VEHICULAR TECHNOLOGY ON ELECTRIC POWERTRAINS FOR FUTURE VEHICLES.

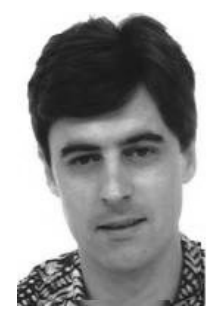

Alain Bouscayrol (M'02) received a Ph.D. degree in Electrical Engineering from the Institut National Polytechnique de Toulouse, France, in 1995. From 1996 to 2005, he was Associate Professor at the University of Lille, France, where he has been a Professor since 2005. Since 2004, he has managed the national network on Energy Management of Hybrid Electric Vehicles France. He has initiated the Energetic Macroscopic Representation (EMR) in 2000 for the description and the control of energetic systems. His research interests at the L2EP include graphical descriptions for control of electric drives, wind energy conversion systems, railway traction systems, hybrid electric vehicles and hardware-in-the-loop simulation. 